\title{
Surface modification of severe plastically deformed ultrafine grained pure titanium by plasma electrolytic oxidation
}

\author{
F. Reshadi, G. Faraji*, M. Baniassadi, M. Tajeddini
}

School of Mechanical Engineering, College of Engineering, University of Tehran, Tehran 11155-4563, Iran.

*Corresponding author, email: ghfaraji@ut.ac.ir, Tel/Fax: +982161119966.

\begin{abstract}
Severe plastic deformation is the best method for processing ultrafine grained (UFG) high strength commercially pure titanium (CP Ti) without any toxic and harmful elements for biomedical implants. Besides, because of the vital importance of the surface bioactivity of a medical implant, this paper studies the effect of Plasma electrolytic oxidation (PEO) process of UFG CP Ti processed by equal channel angular pressing (ECAP). The aqueous electrolyte chosen for PEO process was prepared by mixing $0.15 \mathrm{M}$ calcium acetate hydrate and $0.075 \mathrm{M}$ sodium hypophosphite hydrate at a ratio of 1:1 wt.\%. The results showed that in PEO-coated coarse-grained (CG) CP Ti, the dominant components are oxygen and titanium, while the two principal elements in the coating of UFG CP Ti are oxygen and calcium. It was revealed from EDS and X-ray diffractometry analysis that the more HA and higher content of Ca and $\mathrm{P}$ is formed on the UFG Ti coated sample in comparison with those on coarse-grained Ti coated. The overall $\mathrm{Ca} / \mathrm{P}$ ratio in the layer was determined as 1.65 and 1.70 for the cases of CG CP Ti and UFG CP Ti, respectively. Also, a few numbers of microcracks were obtained on the PEO-coated UFG CP Ti sample compared to those in PEO-coated CG CP Ti. The microhardness of PEO-coated UFG CP Ti was 3275 MPa which was noticeably higher than the microhardness of UFG CP Ti. The electrochemical impedance spectroscopy (EIS) tests were carried out at room temperature using Ringer's solution. EIS test results indicated that the corrosion resistance of PEO-coated UFG CP Ti was greater than non-coated CP Ti and UFG CP Ti. Furthermore, the PEO-coated UFG CP Ti showed more protection against corrosion compared to PEO-coated CG CP Ti. Finally, it is very promising that UFG Ti with PEO surface modification would be a suitable candidate for replacement of Ti-6Al-4V alloy implants containing toxic elements of $\mathrm{Al}$ and $\mathrm{V}$.
\end{abstract}

Keywords: Ultrafine grained; Ti; Severe plastic deformation; Surface modification; Plasma electrolytic oxidation; Hydroxyapatite. 


\section{Introduction}

Due to the unique properties such as high strength to weight ratio, excellent biocompatibility, inherent ability to osseointegration, relatively low modulus, good fatigue strength, formability, machinability and exceptional corrosion resistance, titanium and its alloys are widely used in different industries especially in biomedical devices including surgical implements and implants [1-3]. The CP Ti and titanium alloy Ti-6Al-4V specified as grades 1 to 5 according to the American Society for Testing and Materials (ASTM) are the most prevalent alloys preferred for the manufacturing of titanium implants. Among Ti grades 1 to 4 of unalloyed $\mathrm{CP}$ Ti, grades 1 and 2 are most suitable for using in implants provided that the lower strength problem be solved. Although Ti-6Al-4V alloy has higher strength compared to grade 2 titanium, several reports indicate concerns relating to toxic long term effect of $\mathrm{V}$ and $\mathrm{Al}$ and its adverse reaction with body tissues [4-6]. From the other hand, grade 2 titanium has a lower elastic modulus than of Ti-64 which is more desirable in implants because of avoiding stress shielding and the associated bone resorption [7]. However, grade 2 titanium shows the low mechanical strength which stems from its original coarse-grained (CG) conventional form. This deficiency could be compensated by refining its grain structure through severe plastic deformation (SPD) methods. Equal channel angular pressing (ECAP) proposed by Segal is one of the most common SPD methods in which ultrafine grained (UFG) and nanograined structures are achieved by pressing the metal billet through an angular channel [8]. The schematic of ECAP process is illustrated in Fig. 1. To achieve optimal results, the process may be repeated several times which results in a uniform and ultrafine microstructure throughout the bulk of the metal [7]. The occurrence of cracking and segmentation during deformation brings about difficulties in the processing of titanium by ECAP at room temperature [9].

Several experimental and theoretical studies have been carried out to investigate the effect of ECAP parameters such as die angles, pressing speed, temperature, the number of passes and back pressure on the microstructure and mechanical properties of nanostructured titanium [10-14]. Gunderov et al. [10] studied the evolution of microstructure, macrostructure and mechanical behavior of pure Ti during the thermo-mechanical ECAP process via the conform scheme. They observed that the microstructure is more refined with increasing number of passes. Raab et al. [13] investigated the ECAP process of CP Ti at low temperatures. The results indicated that the decrease of ECAP temperature and the increase of hydrostatic pressure at the deformation zone would result in finer grains and enhanced mechanical properties.

In addition to mechanical strength, corrosion resistance is a major issue regarding dental implants. Although CP Ti and Ti alloys have high corrosion resistance, it could be enhanced by other techniques such as alloying titanium with other noble metals (platinum group metals), surface coating and 
microtexture and microstructure evolution [15]. There are several conflicting reports about the effect of grain refinement on the corrosion resistance behavior of CP Ti. The complicated relationship between grain refinement resulted from SPD methods, and corrosion resistance of achieved UFG CP Ti could be interpreted regarding a competition between the adverse effect of the inhomogeneous microstructure and the positive effect of the grain size reduction [16]. Also, it has been observed that in comparison with grain size, texture is the dominant factor controlling the corrosion properties of $\mathrm{CP} \mathrm{Ti}$ [17].

Besides, because of the vital importance of the surface bioactivity of a medical implant, several surface modification techniques were investigated. In the last decades, surface anodization has attracted researcher's attentions as an effective method to provide the surface of Ti with a stable inert oxide film leads to enhancement of corrosion resistance. It should be noted that the surface characteristics of CP Ti such as roughness and morphology play a major role in increasing the lifetime of the implant and stimulating biocompatibility and osseointegration. Moreover, several techniques have been developed to fabricate a bioactive surface by applying Hydroxyapatite (HA) oxide coatings on the surface of CP Ti [18]. Advances in surface modification of Ti for implant application have led to the development of Plasma electrolytic oxidation (PEO) as an anodization technique being carried out in high voltage. The schematic of PEO setup was presented in Fig. 1. Compared with conventional anodization, PEO is a rapid and straightforward process in which metal surface is converted into a ceramic-like layer (rutile) [19]. It has been approved that coatings synthesized by PEO have superior characteristics such as excellent corrosion protection, favorable wear resistance, high hardness and enhanced bonding strength with substrate [20].

Different researches have been performed on surface modification of $\mathrm{Ti}$ and its alloys by PEO in literature. Simka et al. [21] incorporated $\mathrm{Ca}$ and $\mathrm{P}$ into the emerging passive layer during anodic oxidation on a titanium substrate, and it was proved that the modified titanium presents higher resistance to corrosion in the investigated environment than unmodified titanium. Shokuhfar et al. [22] studied the growth characteristics and corrosion behavior of the fabricated ceramic coating on titanium by PEO procedure in different electrolytes. They demonstrated that the spark voltage of oxide layer has the significant influence on the surface morphology, size and homogeneity of micro-pores. The effect of PEO pre-treatments on the adhesive bonding of titanium was investigated using lap-shear tests by Aliasghari et al. [23]. It was corroborated that the pre-treatments influence on the lap-shear strength is not noticeable.

To the best knowledge of the authors, though several studies were done on PEO coating of conventional alloys [24-26], a few studies have been allocated to apply PEO procedure on UFG CP Ti Grade 2. The main objective of this article is to remove the limitations of CP Ti application in the field of implant 
manufacturing. In the first stage of this research, four passes ECAP process is implemented to prepare UFG CP Ti with excellent mechanical strength from CG CP Ti. In the next stage, PEO process is employed to form a porous bioactive coating on the surface of UFG CP Ti. In this paper, several characterizations including the investigation of surface and cross-sectional morphologies, elemental and phase composition, microhardness, the corrosion resistance of the PEO-coated and non-coated CG and UFG CP Ti samples were carried out.

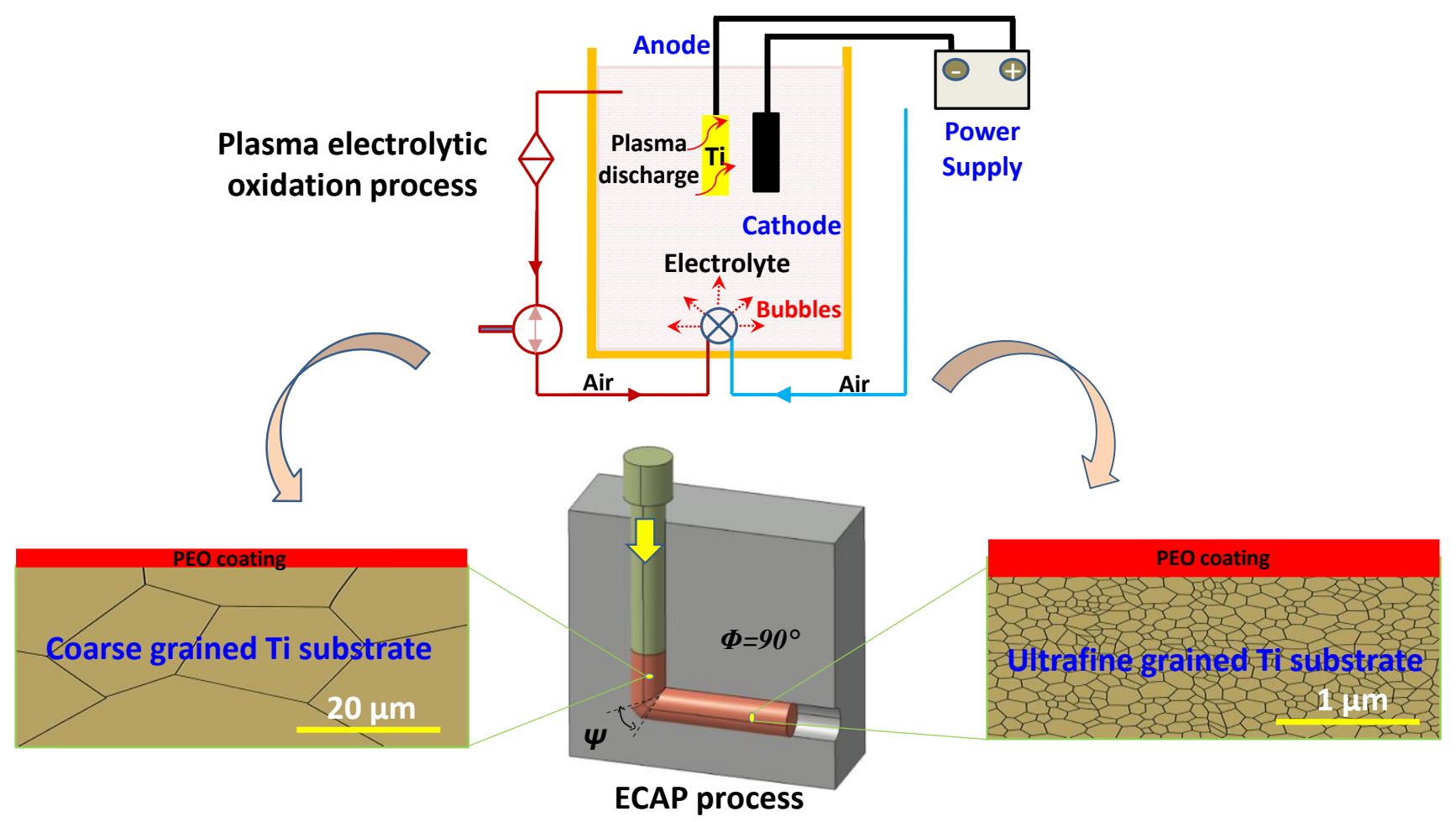

Fig. 1. Schematic illustration of ECAP and plasma electrolytic oxidation processes.

\section{Materials and methods}

\subsection{ECAP procedure}

Round bars $10 \mathrm{~mm}$ diameter CP Ti Grade 2 were used as the starting material. The impurity constituents in this material were $0.20 \%$ wt. Oxygen, $0.03 \%$ wt. Iron, $0.01 \%$ wt. nitrogen, $0.02 \%$ wt. Carbon, $0.002 \%$ wt. Hydrogen. An ECAP die with $90^{\circ}$ channel angle was manufactured from hot worked tool steel and hardened to 50 HRC. The ECAP process was conducted by pressing the bars through a die having two channels with the same circular cross-sectional areas intersecting each other at angle 90 degrees (Fig. 1). The Bc route was chosen in the deformation procedure to ensure yielding equiaxed 
grains in the microstructures of products. Four passes ECAP process via route $\mathrm{B}_{\mathrm{c}}$ were applied to the $\mathrm{Ti}$ bars at a constant temperature of $400{ }^{\circ} \mathrm{C}$. Namely, the Ti bars were rotated 90 degrees clockwise around the pressing axis between the consecutive passes. A graphite-based slurry was used on ECAP channel as a lubricant to reduce the friction between Ti bars and die surfaces during deformation. The picture ECAP die and Ti sample during the process were shown in Fig. 2. To achieve a smooth surface finish; ECAPed sample was then machined to the diameter of $8 \mathrm{~mm}$.

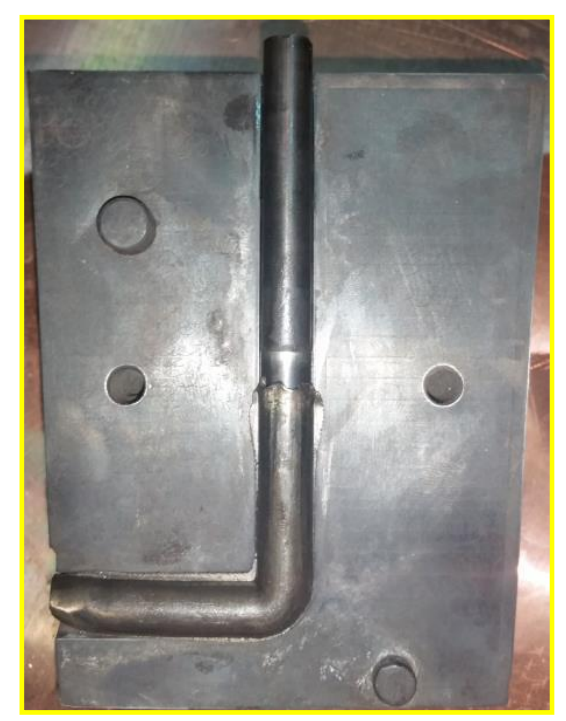

Fig. 2. ECAP die half and Ti sample during processing.

\subsection{Plasma electrolytic oxidation procedure}

Disk-shaped samples having $1 \mathrm{~mm}$ thickness were cut from the as-received CG CP Ti and UFG CP Ti ECAP processed bars by implementing wire-cut electro discharge machining perpendicular to the longitudinal axis of bars. The surfaces of disk-shaped specimens were ground with up to $2000 \mathrm{SiC}$ sandpaper. To prepare the surface for anodization process, the samples were degreased in a solution of acetone, ethanol and distilled water by ultrasonic cleaner and dried in warm air at $40{ }^{\circ} \mathrm{C}$. The anodization setup consists of a glass electrolytic cell, platinum cathode, AC power supply and a cooling system to maintain the temperature of the electrolyte in the range of room temperature. The aqueous electrolyte was prepared by mixing $0.15 \mathrm{M}$ calcium acetate hydrate and $0.075 \mathrm{M}$ sodium hypophosphite hydrate at a ratio of $1: 1 \mathrm{wt} . \%$. The samples were used as an anode, and the anodization process was carried out by applying constant current density of $350 \mathrm{~mA} \cdot \mathrm{cm}^{-2}$ for $8 \mathrm{~min}$.

\subsection{Microstructure and mechanical tests}


To investigate the effect of ECAP process on the microstructure, transverse sections were cut and prepared through standard metallurgical techniques. Dog bone mechanical tensile test samples with a gauge of $20 \mathrm{~mm}$ and fillet radius of $2 \mathrm{~mm}$ according to standard ASTM-E8 were prepared from CG CP Ti and UFG CP Ti products. Tensile tests were performed by applying machine head velocity of $1 \mathrm{~mm} / \mathrm{min}$ at room temperature using an Instron universal testing machine. The mechanical characteristics including yield strength (YS), ultimate tension strength (UTS) and elongation to failure were determined. Furthermore, the surface microhardness was measured using a 401MWD hardness tester according to Vickers procedure at room temperature. For this purpose, a load of $200 \mathrm{gf}$ with a holding time of $10 \mathrm{~s}$ was applied. The average of 10 measurements was used as sample hardness.

\subsection{Coating evaluation tests}

Scanning electron microscope (SEM) Hitachi S4160 was used to investigate the surface and crosssectional morphologies of the applied anodic film. The elemental composition was analyzed by a microwave energy dispersive X-ray (EDS) incorporated into the SEM system. The pore density of anodic layer was analyzed by use of an image processing software package ImageJ. The electrochemical impedance spectroscopy (EIS) was performed using an EG\&G 273A potentiostat to determine the electrical properties of the anodic film. A three-electrode cell was chosen for EIS tests in which $\mathrm{Ag} / \mathrm{AgCl}$ electrode and Platinum grid were used as the reference and counter electrodes for potential measurement, respectively. The working electrodes consisting of CP Ti, UFG CP Ti, and PEO-coated UFG and CP Ti were masked with lacquer to expose an area of $0.4 \mathrm{~cm}^{2}$. EIS tests were carried out at room temperature with $10 \mathrm{mV}$ of amplitude perturbation and a frequency range between $10^{5}$ and $10^{-1} \mathrm{~Hz}$ using Solarton 1260. The solution chosen as an electrolyte was Ringer's solution $(8.6 \mathrm{~g} / 1 \mathrm{NaCl}, 0.3 \mathrm{~g} / \mathrm{KCl}$ and $0.33 \mathrm{~g} / \mathrm{l}$ $\mathrm{CaCl}_{2} \cdot 2 \mathrm{H}_{2} \mathrm{O}$ ) for all studies [27]. The EIS results were simulated using software Zview which applies a least-squares approximation to adjust the experimental data. Grazing incidence X-ray diffraction (XRD, Philips, X'pert) was used to analyze the phase composition of PEO-coated CG CP Ti and PEO-coated UFG CP Ti in which the step size and scanning rate were chosen to be 0.01 and $2 \mathrm{deg} / \mathrm{min}$, respectively.

\section{Results and discussion}

The SEM micrographs of the CG CP Ti and UFG CP Ti processed via four passes ECAP were depicted in Fig. 3. As it can be seen, significant grain refinement is achieved by applying four passes of ECAP. It was shown that after applying the initial pass of ECAP, a pure shear zone is created in CP Ti 
and grains get stretched along the longitudinal direction [13]. Previous investigations have corroborated that the twinning plays the major role at the initial pass of ECAP, while the deformation mechanism changes to dislocation slip system relied on the route type of ECAP [28]. That is to say, by conducting the first pass of ECAP a large number of twins are formed in the longitudinal direction. Increasing the number of ECAP passes to four would lead to a simultaneous increase of strength and ductility which stems from increased fraction of high angle grain boundaries and the improved homogeneity of the microstructures [29]. Namely, increasing the ECAP passes to four passes results in decreasing of shear bands width and many dislocation cell blocks appear in band structures leading to subgrain formation [30]. It is worth mentioning that the density of dislocation in the subgrain boundaries is relatively high and the newly developed grains have high angle grain boundaries. According to previous studies, the main mechanisms of grain refinement are restoration, predominantly recovery and partial recrystallization at temperatures $200-450{ }^{\circ} \mathrm{C}[31,32]$. Moreover, the saturated mechanical properties are achieved after 4-6 passes of ECAP [10,33].
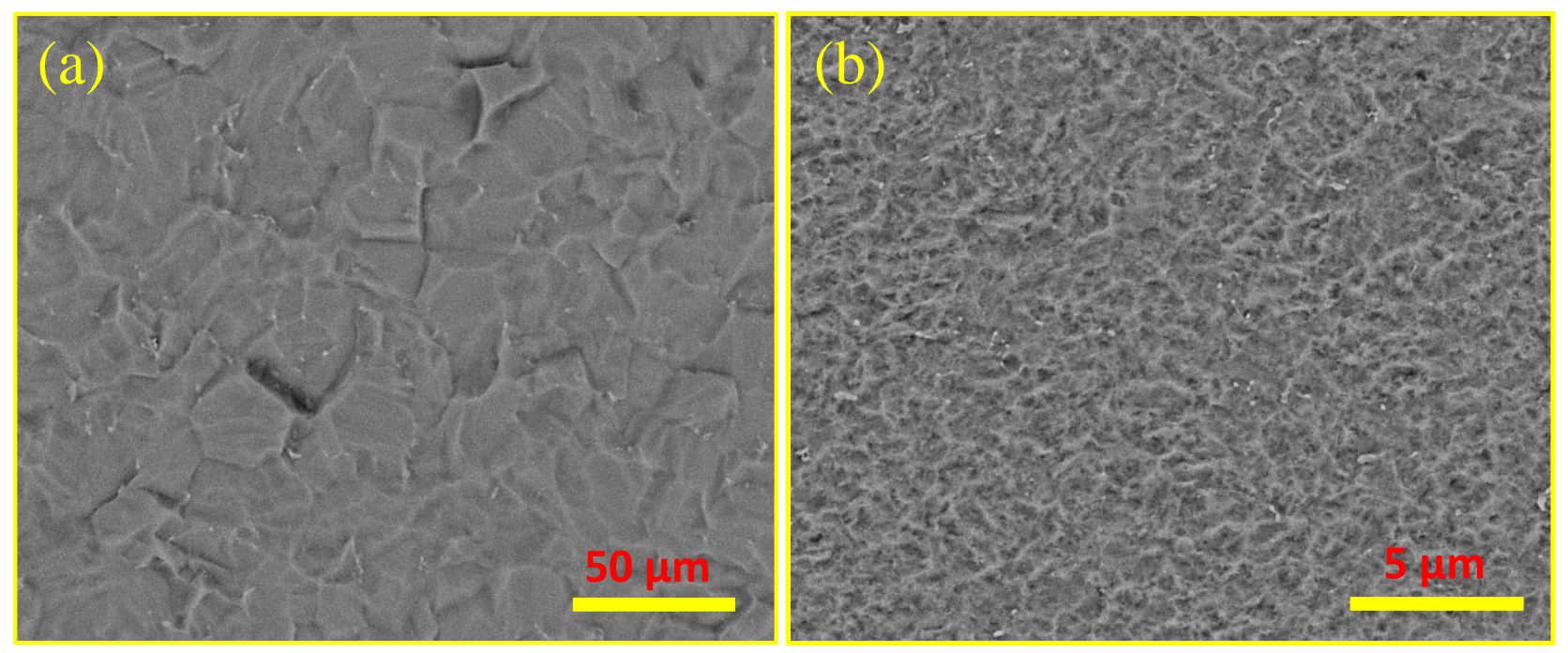

Fig. 3. SEM microstructures of (a) CG CP Ti and (b) UFG CP Ti processed by four passes ECAP.

Using an image analysis software, ImageJ, the average grain size for CG CP Ti and UFG CP Ti was determined as $\sim 25 \mu \mathrm{m}$ and $\sim 100-150 \mathrm{~nm}$, respectively. As it could be seen, the original grain shape is almost equiaxed while applying four passes of ECAP led to a non-directionally submicron morphology with a high fraction of high-angle grain boundaries.Because the determination of the grain size of UFG Ti using SEM image of Fig. 3 is relatively hard, the XRD patterns of CG CP Ti and UFG CP Ti presented in Fig. 4 was used. The full width at half maximum (FWHM) values and crystallite size on UFG CP Ti surface were determined through XRD pattern by implementing Scherrer formula [34]: 
$B(2 \theta)=\frac{k \lambda}{L \cos \theta}$

Where $B$ is the FWHM in radians, $k$ is a constant near to unity, $\lambda$ is the wavelength X-rays in nm, $\theta$ is the diffraction angle in degrees and $L$ is the average crystallite size. The XRD analysis showed the new crystallite size after applying four passes of ECAP have reached to about $\sim 130 \mathrm{~nm}$ which is almost lower than the average size achieved from SEM images. It should be noted that the Scherrer formula neglect the effect of lattice strain and instrumental factors on broadening of peaks which leads to underestimating of crystallite size [35].

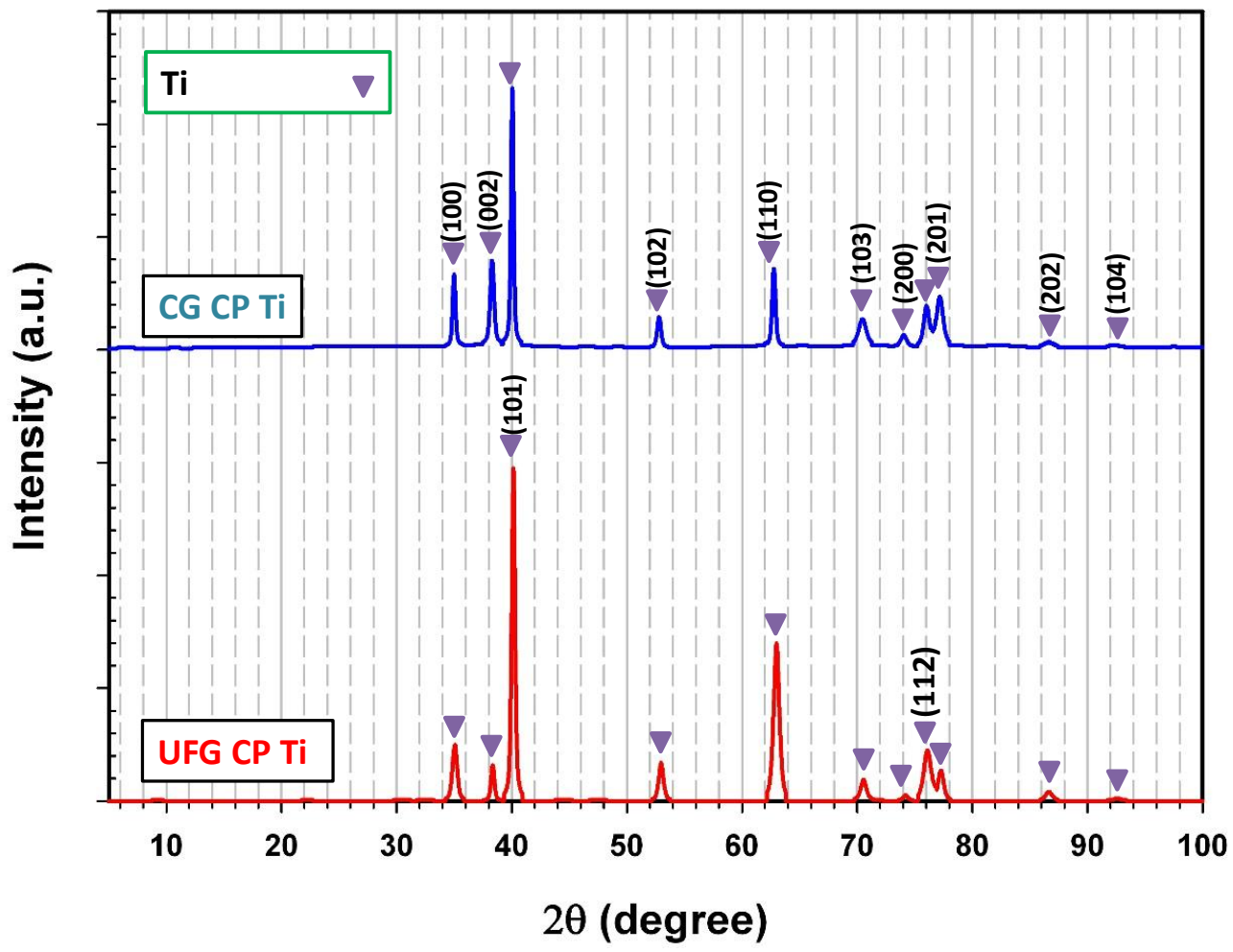

Fig. 4. XRD patterns of CG CP Ti and UFG CP Ti.

The mechanical properties resulted from tensile tests conducted on CG CP Ti and UFG CP Ti samples were summarized in Fig. 5. As a rule of thumb, grain refinement brings about enhancing the mechanical strength of which is mathematically modeled as a Hall-Petch rule [36]. It can be observed that after applying four passes of ECAP, both YS and UTS of CG CP Ti simultaneously increased from 292.5 to 780.6 $\mathrm{MPa}$ and 551.0 to $970.5 \mathrm{MPa}$, respectively. Moreover, the elongation to failure decreased from $21 \%$ to $15 \%$. Compared to Ti64, YS and UTS values for UFG CP Ti are almost similar to those of Ti64 [37]. Additionally, the elongation to failure for UFG CP Ti is noticeably greater than that of Ti64. 
According to Fig. 6, the microhardness of $\mathrm{CP}$ Ti was increased after applying four passes of ECAP from $1560 \mathrm{MPa}$ to $2430 \mathrm{MPa}$. It was also revealed that PEO-coated CG CP Ti and PEO-coated UFG CP Ti samples have a microhardness of $3190 \mathrm{MPa}$ and $3275 \mathrm{MPa}$, respectively. These values are significantly higher than those of CG CP Ti, and UFG CP Ti samples while almost close to microhardness of Ti64 [37].

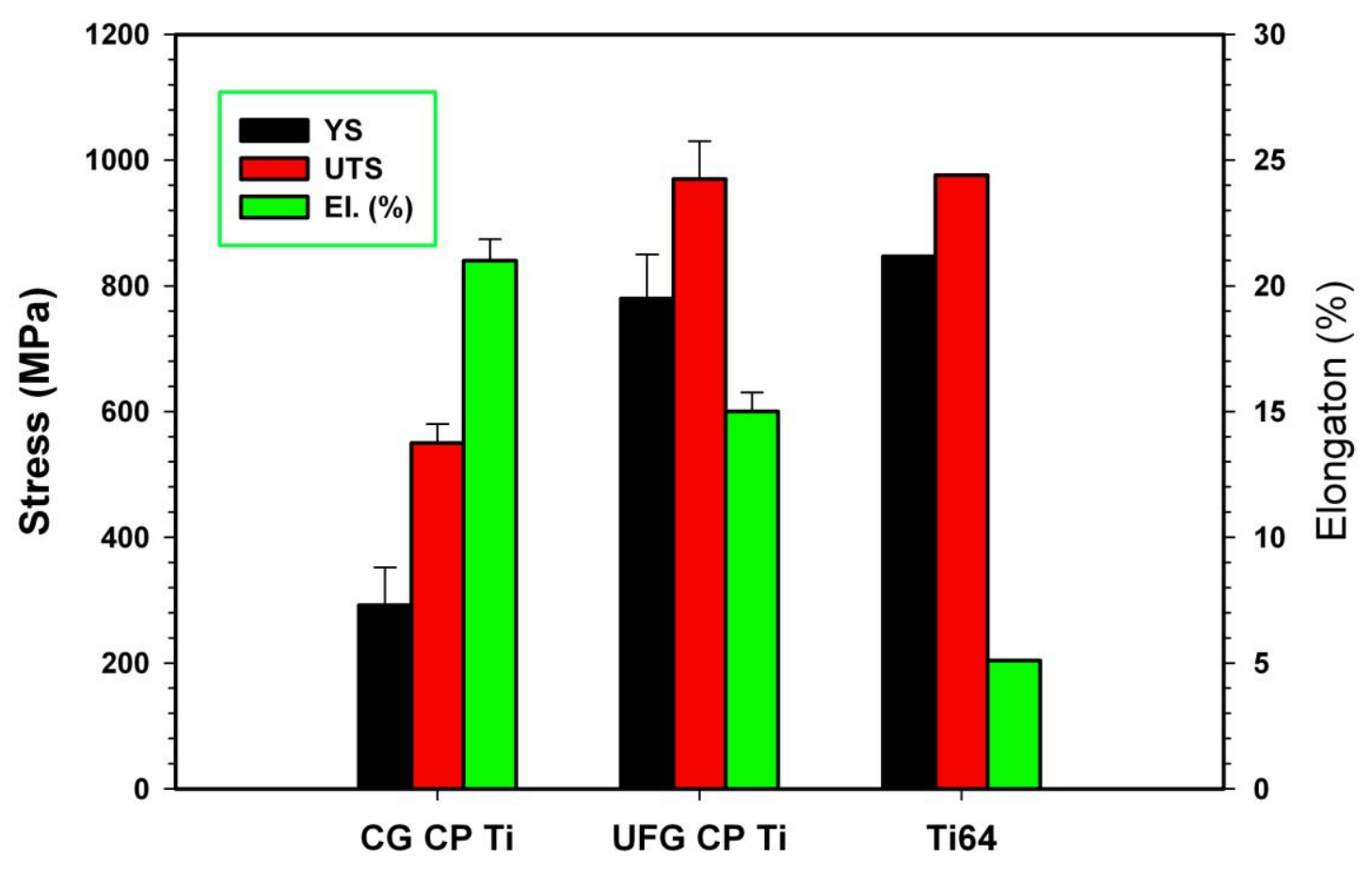

Fig. 5. Strength and ductility of CG CP Ti, UFG CP Ti and Ti64 samples. 


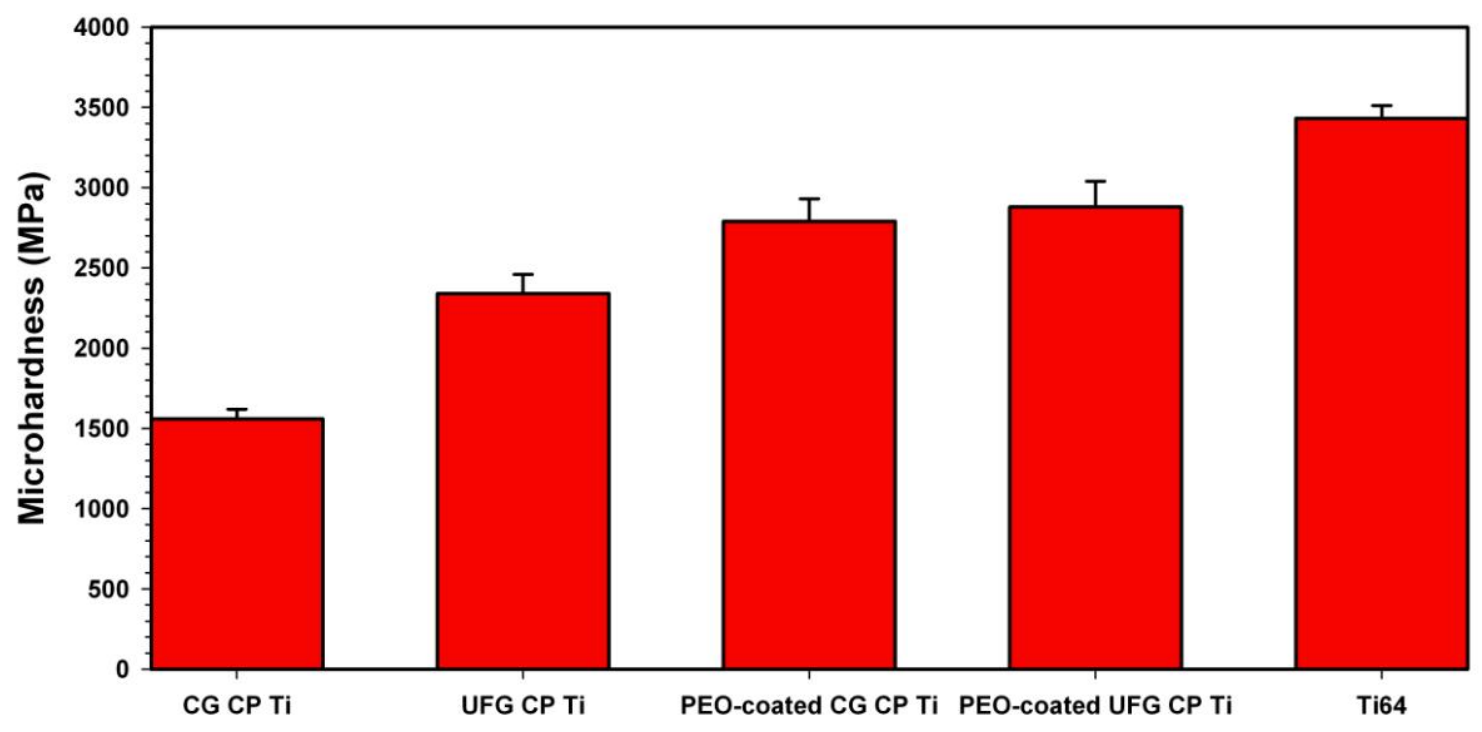

Fig. 6. Microhardness of CG CP Ti, UFG CP Ti, PEO-coated CG CP Ti, PEO-coated UFG CP Ti and Ti64 samples.

It is of great importance that the electric field plays the major role in the morphology of the anodic film. The response of potential during surface anodization of CG CP Ti and UFG CP Ti versus time obtained at constant current was presented in Fig. 7. As it can be seen, the potential versus time curve can be divided into three typical regions [38]. Firstly, the potential ascends linearly in the region $I$ associated with a traditional anodizing stage in which a thin oxide layer is formed on the sample surfaces [39]. In this stage, no spark was detected on the surface of the specimen. Although the potential increases as the time passes in region II, the slope of the curve decreases gradually until reached the potential upper limit value [40]. In this stage, the sparks begin to develop on the surface of the specimen, and the gas formation at the film surface is enhanced. Subsequently, in region $I I I$, the potential remains relatively constant, and the sparks are augmented, and the numbers multiplied noticeably [41]. Comparing two curves of Figs. 7(a) and (b), it is observed that the region I during anodization of CG CP Ti is smaller than that of UFG CP Ti. This means that the sparks begin to develop sooner in the time period. However, the potential upper limit value is achieved earlier in the case of UFG CP Ti anodization which results in a larger region III. However, the formation of large sparks is stabilized, and the PEO process is carried out more efficiently. It is worth mentioning that the region II of PEO process during which sparks are generated begins as the voltage exceeds the breakdown voltage of insulation oxide layer developed on the surface of the substrate [42]. In region II, discharge channels are generated at the weak point of insulation oxide film on the substrate which results in the formation of porous layer [43]. The smaller region I for PEO-coated CG CP Ti compared to the PEO-coated UFG CP Ti one can be interpreted by considering the difference of 
microstructures of both substrates. It is clear that after applying four passes of ECAP on the CG CP Ti, a sub-microcrystalline structure with high energy grain boundaries is produced. It has been proved in literature that the high energy grain boundaries enhance the chemical reaction of the substrate which leads to the formation of thicker oxide film on the surface of UFG CP Ti compared to CG CP Ti [44, 45]. This phenomenon, in turn, brings about increase of dielectric breakdown of the anodic oxide film on UFG CP Ti substrate.
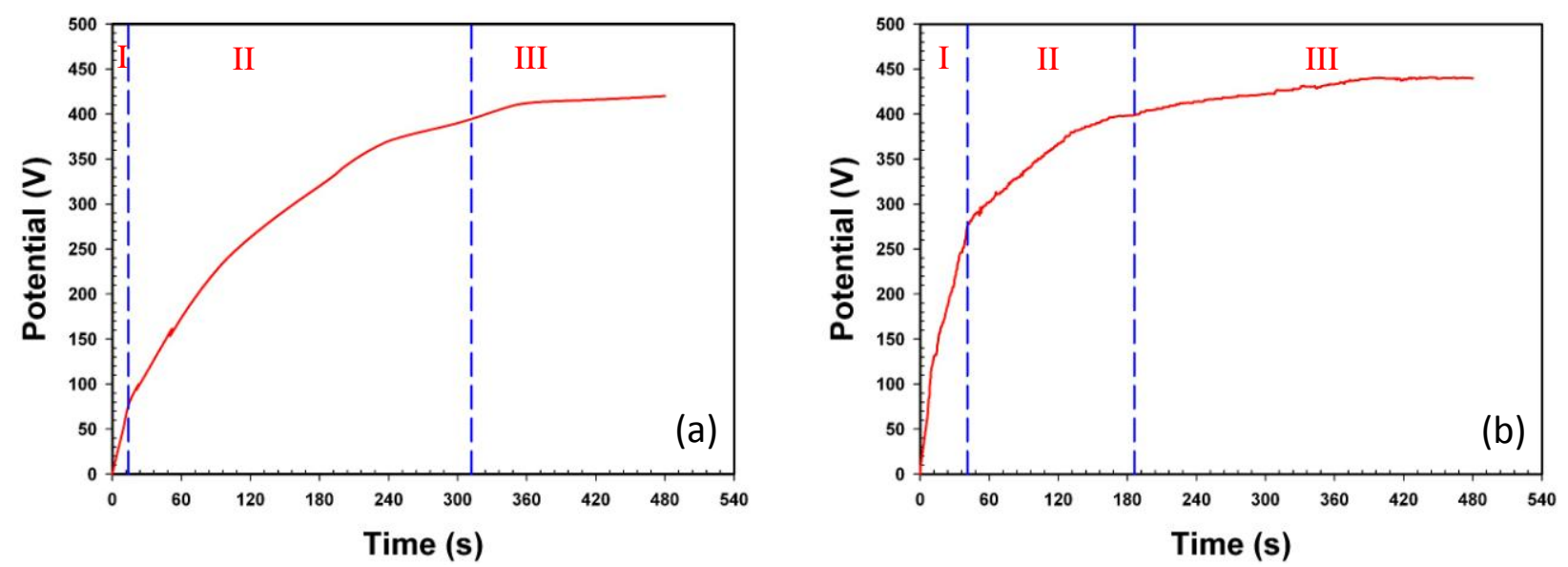

Fig. 7. Cell voltage during PEO process for of (a) CG CP Ti and (b) UFG CP Ti during 480 seconds.

The SEM micrographs of Fig. 8 indicate the progressive formation and growth of PEO coating on the surface of CG CP Ti and UFG CP Ti substrates. It can be seen that for both cases, the morphology of oxide layer contains many micropores and nanopores $(\sim 10 \mu \mathrm{m}$ to $\sim 100 \mathrm{~nm})$ distributed homogeneously on the surfaces which are a typical characteristic of PEO coating. To be specific, the major circular and elliptical pores formed during micro-arc discharge procedure raised above the surface as analogous to volcano vent. Micro-cracks were detected on the surface of the anodized film which could be originated from different issues such as gas generation, thermal stress, and the shrinkage during drying. Comparing two morphologies shown in Fig. 8, the PEO coating on CG CP Ti has smaller pores with more cracks extending on the surface. Additionally, the formation of micro and nanosized HA crystals in the coating is more evident for the case of PEO-coated UFG CP Ti in comparison with the CG sample. As known, CaP containing coatings enhance the new bone osteogenesis wich is vital for biomedical implants [46]. Though, grain refinement itself has an improved effect on cell morphology, adhesion, proliferation, and differentiation [47]. So, when the grain refinement is applied simultaneously with PEO coating having HA particles, it may significantly enhance the osseointegration beside mechanical properties 
improvements. Also, using grain refinement provides high strength pure Ti grade 2 to be used instead of a Ti64 alloy including toxic and harmful elements of $\mathrm{V}$ and $\mathrm{Al}$ elements.

The cross-sectional morphologies of oxide layers associated with PEO-coated CG CP Ti and PEO-coated UFG CP Ti are presented in SEM micrographs of Fig. 9. It was revealed that the interface of substrates and oxide layer present undulations which were more intense for CG CP Ti substrate. The average thickness of oxide layer for PEO-coated CG CP Ti and PEO-coated UFG CP Ti were estimated to be $\sim 24.4 \mu \mathrm{m}$ and $\sim 36.5 \mu \mathrm{m}$, respectively. For both cases, it was observed that the oxide layer is composed of a porous outer layer and a compact inner layer adjacent to substrate surface as already seen by other researchers $[48,49]$. It is noted that for the case of PEO-coated UFG CP Ti, the compact inner layer is more uniform and thicker compared to the PEO-coated CG CP Ti one. In fact, the compact inner layer is not formed properly on the substrate for PEO-coated CG CP Ti. It is also of great importance that it has been proved by other researchers that the compact inner layer plays the major role in corrosion protection of substrate and the corrosion resistance of porous outer layer is negligible compared to the one of compact inner layer.

An arbitrary area of $100 \times 100 \mu \mathrm{m}^{2}$ was chosen for statistical analysis. To evaluate the pore size, Feret's diameter was used which is the longest distance between any two points along the pore boundary. The results were shown in Fig. 10. For the case of CG CP Ti anodization, the average Feret's diameter and area of pores were measured as $1.49 \mu \mathrm{m}$ and $1.43 \mu \mathrm{m}^{2}$, respectively. While, the pore density of the anodized film was calculated as 0.050 . The analysis indicates that the Feret's diameter was limited to 0.06 $\mu \mathrm{m}$ and $6.95 \mu \mathrm{m}$, while the surface area of pores varied between $0.004 \mu \mathrm{m}^{2}$ and $12.80 \mu \mathrm{m}^{2}$. This analysis was performed for the case of PEO-coated UFG CP Ti. Namely, the average Feret's diameter and area of pores were measured as $2.31 \mu \mathrm{m}$ and $3.89 \mu^{2}$, respectively. While, the pore density of the anodized film was calculated as 0.095. It is worth mentioning that the Feret's diameter was bounded by $0.09 \mu \mathrm{m}$ and $11.25 \mu \mathrm{m}$, while the surface area of pores fluctuated from $0.01 \mu \mathrm{m}^{2}$ to $33.46 \mu \mathrm{m}^{2}$. By comparing the results, it can be concluded that for the case of UFG CP Ti anodization, larger pores are formed on the surface. This phenomenon is in good agreement with cell voltage curves in Fig. 7 in which larger region III was observed during UFG CP Ti anodization in comparison with CG CP Ti. 


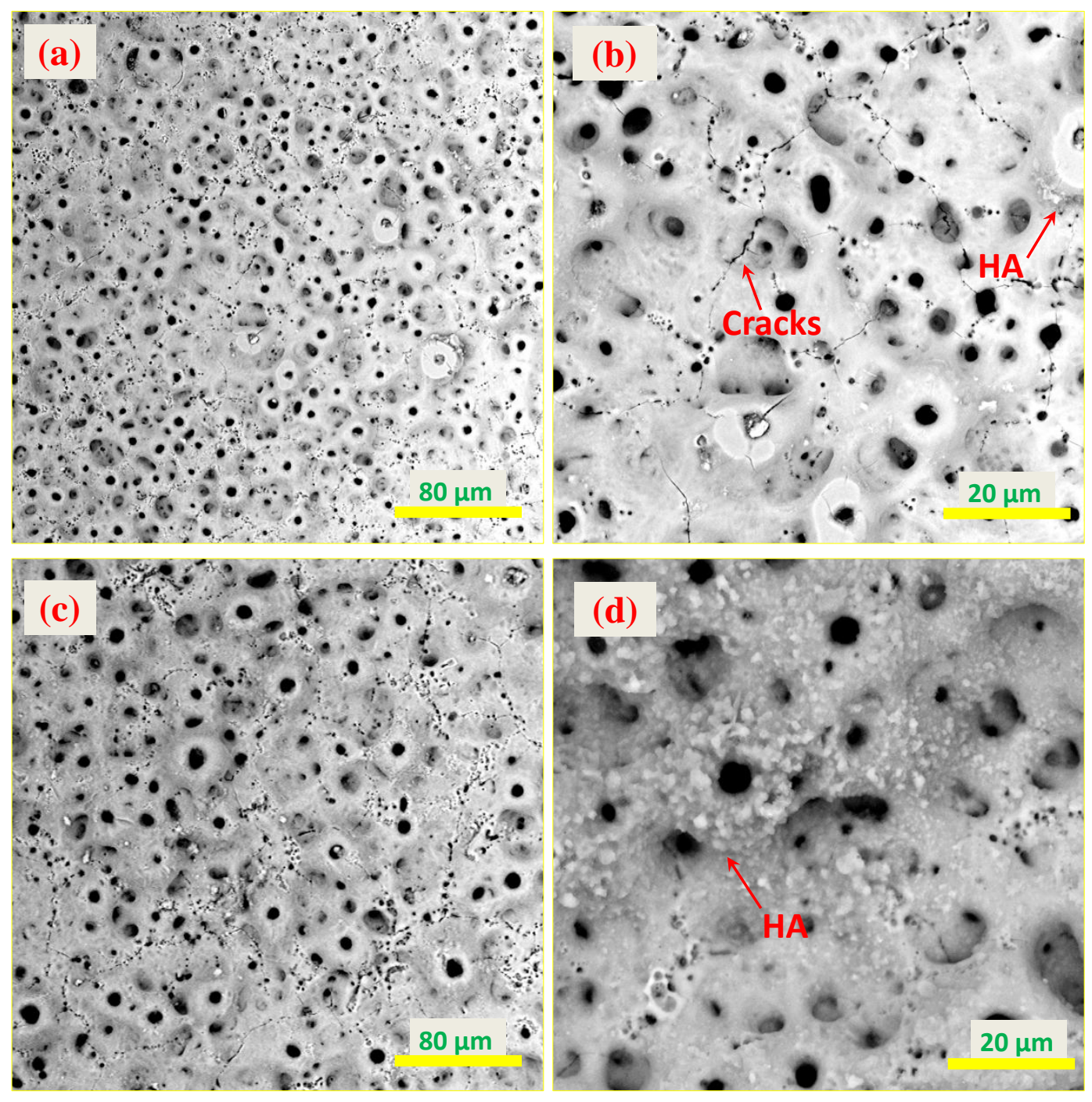

Fig. 8. SEM views of PEO-coated of (a), (b) CG CP Ti surface and (c), (d) UFG CP Ti surface.
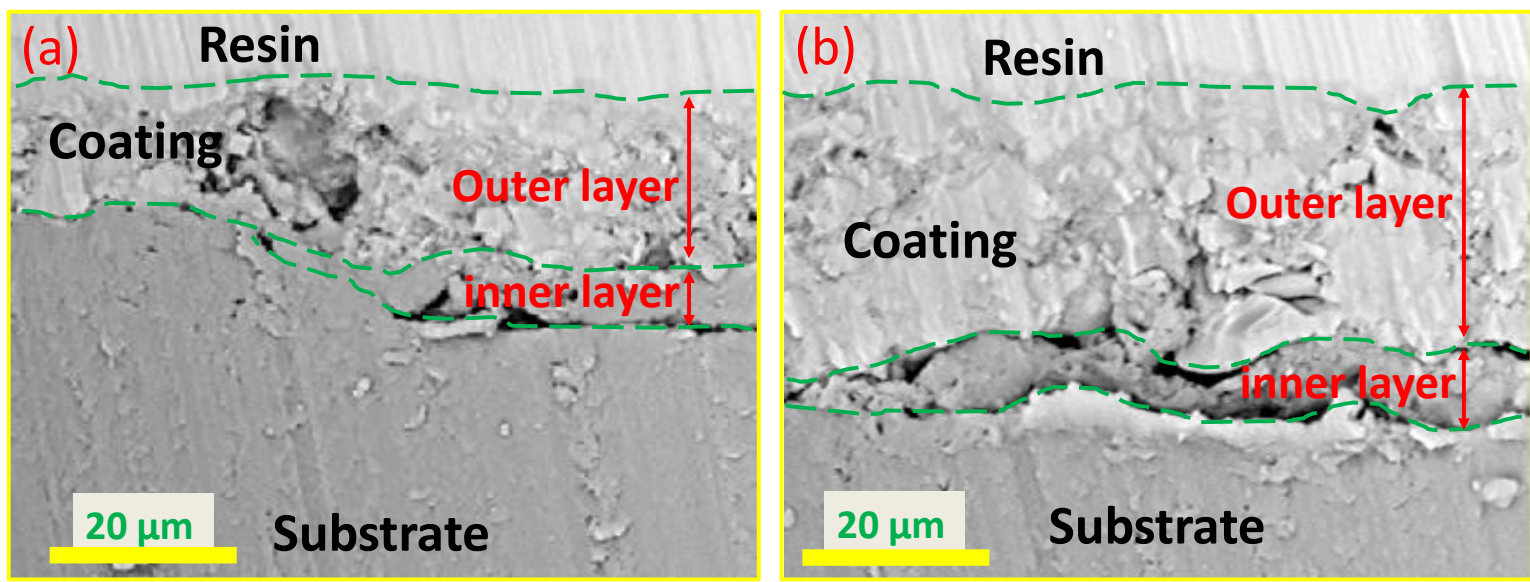

Fig. 9. SEM micrographs showing cross sections of PEO coating formed on (a) CG CP Ti and (b) UFG CP Ti substrates. 

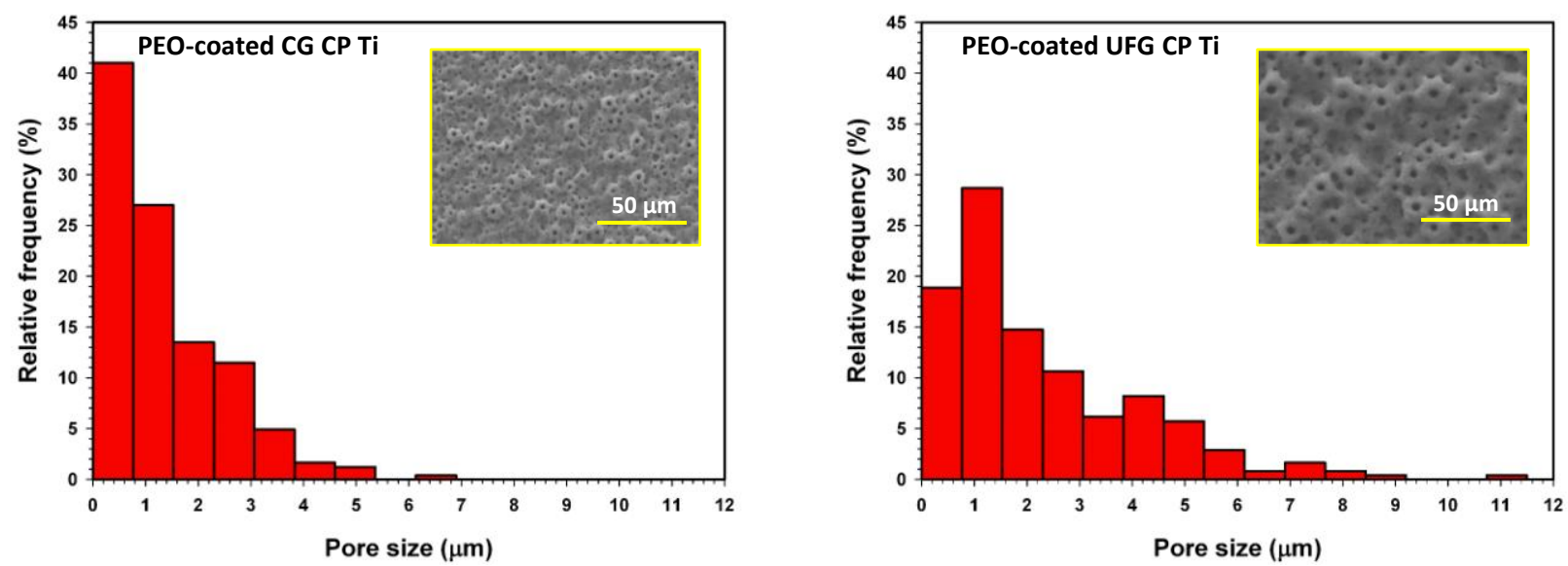

Fig. 10. The distribution of pores size in the coating for PEO-coated CG CP Ti and PEO-coated UFG CP Ti.

As it can be seen in the EDS spectrum presented of Fig. 11, clear peaks of calcium and phosphorus prove that PEO process in solution with calcium and phosphates successfully leads to a buildup of these components in the oxide film. For the case of PEO-coated CG CP Ti, the dominant elements in the layer are oxygen and titanium, while the two major elements in the coating of UFG CP Ti are oxygen and calcium. It was observed that the concentration of calcium and phosphorus elements on the location of cracks and pores are higher than smooth areas. It can be seen that the weight percentages of calcium and phosphorus in the PEO-coated UFG CP Ti are higher in comparison with those of CG CP Ti. The overall $\mathrm{Ca} / \mathrm{P}$ ratio in the layer was determined as 1.65 and 1.70 for the cases of CG CP Ti and UFG CP Ti, respectively, which are so close to $\mathrm{Ca} / \mathrm{P}$ ratio in stoichiometric $\mathrm{HA}(\mathrm{Ca} / \mathrm{P}=1.67)[50]$. 

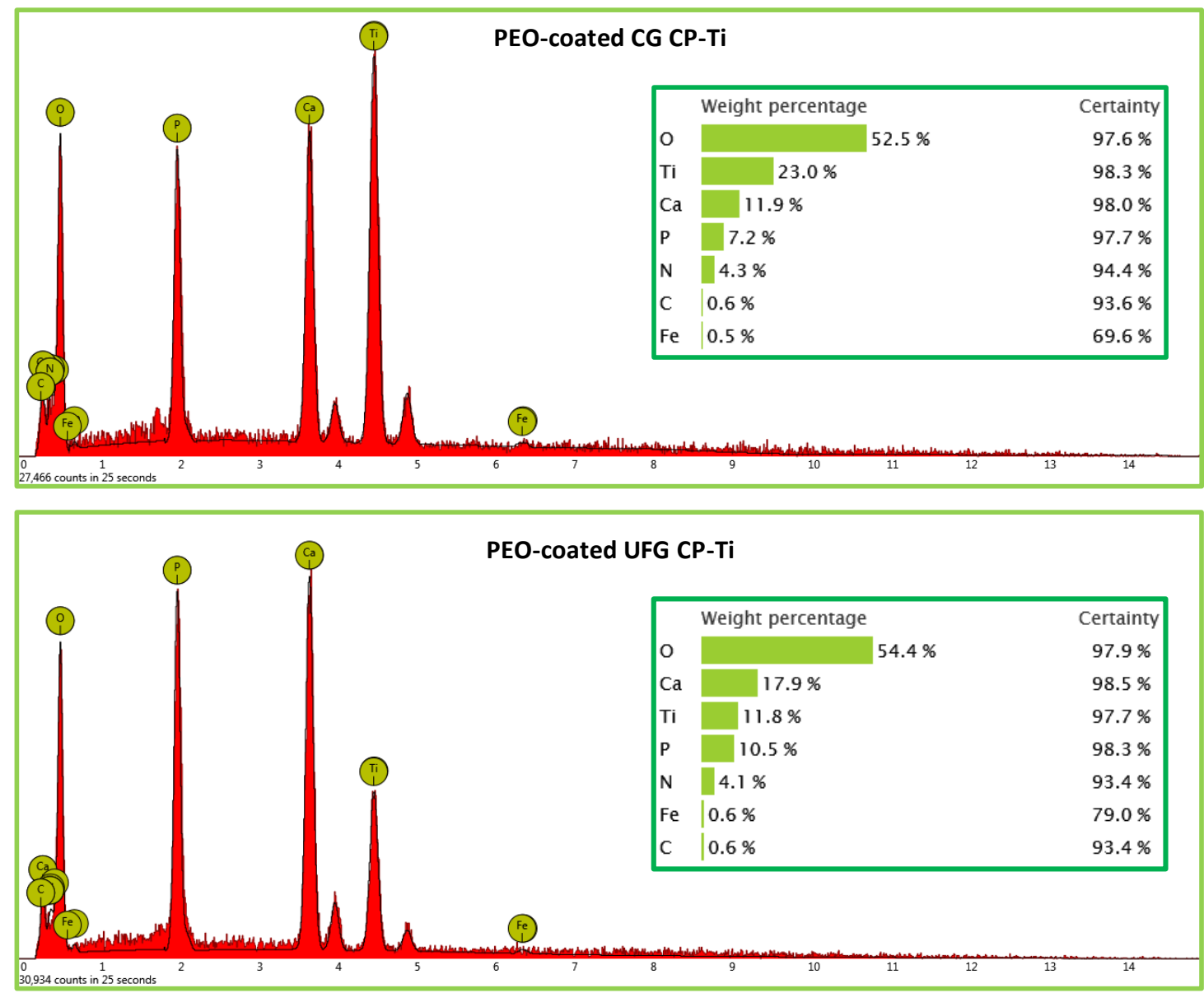

Fig. 11. EDS spectra of PEO-coated CG CP Ti and UFG CP Ti surfaces.

The XRD patterns of PEO-coated CG CP Ti and PEO-coated UFG CP Ti are presented in Fig. 12. It can be observed that for the case of CG CP Ti, the coating has a composite structure composed of titania (anatase, rutile, and brookite) and no diffraction of HA was seen on XRD pattern which could be due to the low concentration of such phase or the presence of HA in amorphous material. Considering Fig. 12, the diffractogram of PEO-coated UFG CP Ti shows several weak peaks which is suggested to be due to the formation of HA crystallites according to standard ICDD X-ray. For both cases, the metastable anatase is the dominant phase compared to stable rutile phase. Furthermore, titania peaks are more intense for the case of PEO-coated UFG CP Ti in comparison with PEO-coated CG CP Ti. This phenomenon could be interpreted by considering the microstructure evolution after applying four passes of ECAP. It has been reported previously that by implementing severe plastic deformation, a sub-microcrystalline structure is fabricated having high energy grain boundaries and structural defects. In fact, atomic diffusivity in the nanocrystalline surface layer is considerably elevated compared to the conventional CG 
polycrystals because grain boundaries act as fast diffusion channels. This enhancement of diffusivity in the nanostructures can be very beneficial for advancing the traditional surface modification methods that rely on various chemical reactions, such as PEO [44, 45, 51-53]. Consequently, the high energy grain boundaries are found to be an appropriate place for $\mathrm{Ca}$ and $\mathrm{P}$ elements to diffuse due to increasing the kinetics of chemical reactions.

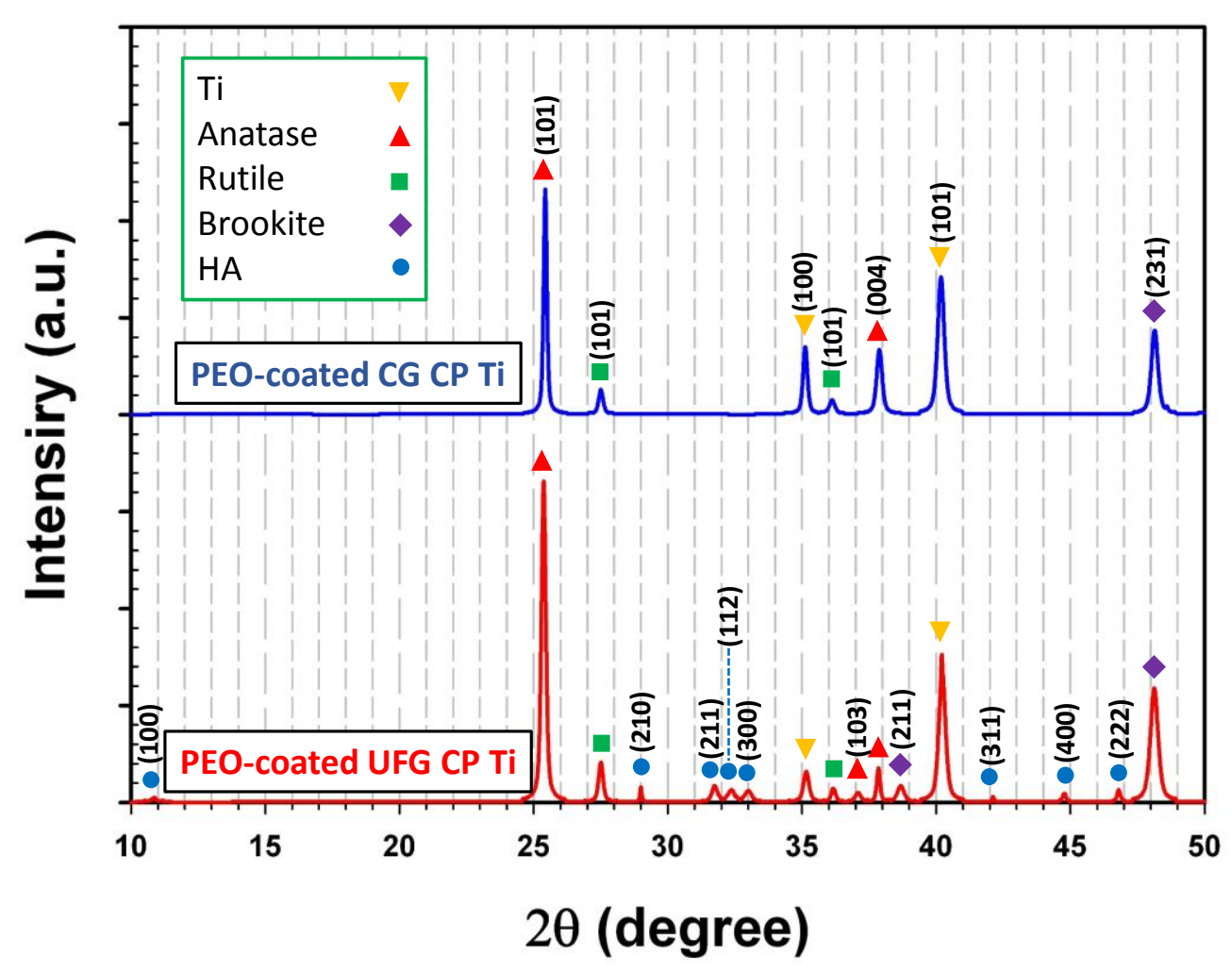

Fig. 12. XRD patterns of PEO-coated CG CP Ti and PEO-coated UFG CP Ti.

The EIS was implemented to investigate the corrosion resistance of the prepared samples as shown in Fig. 13. The equivalent electrical circuit (EEC) for the obtained empirical data is demonstrated in Fig. 14. According to fig. 14(a), the EEC of CG CP Ti and UFG CP Ti includes the following electrical elements, namely a constant phase element $\left(C P E_{1}\right)$ that models the behavior of a double layer (imperfect capacitor) in parallel to charge transfer resistance $\left(R_{c t}\right)$ in series with $R_{S}$ presented for the solution resistance. The EEC of PEO-coated CG CP Ti and PEO-coated UFG CP Ti is composed of $C P E_{1}$ in parallel to $R_{1}$, corresponding to the low frequency characteristics of compact inner layer, $C P E_{2}$ in parallel to $R_{2}$, in association with the high frequency characteristics of porous outer layer and $R_{S}$ representing the solution 
resistance. As is seen in Fig. 13, one-time constant EEC presents an acceptable fitness of simulated curves with the experimental data for non-coated samples. However, for the cases of PEO-coated samples the best agreement between experimental data and simulated data was obtained by considering a two time constants EEC corresponding to the coatings composed of a compact inner layer and a porous outer layer. In order to ensure the goodness of fitness for each sample, the chi-squared $(\chi)$ values were calculated which were of the order of $10^{-3}$ and $10^{-4}$. It has been proved in literature that in PEO procedure the barrier layer is formed due to the applied voltage over the substrate, while the porous layer is fabricated as a result of plasma interaction with the substrate [54-56]. As shown in Fig. 13, initially PEO-coated UFG CP Ti shows higher corrosion resistance in comparison with CP Ti and UFG CP Ti and PEO-coated CG $\mathrm{CP} \mathrm{Ti}$ at low frequencies. Furthermore, it could be drawn from Bode graphs that $\mathrm{CP}$ Ti has lower protective property against corrosion compared to UFG CP Ti. This phenomenon could stem from different issues. Firstly, the enhancement of corrosion resistance may be attributed to grain refinement and the subsequent dispersion of impurities in the microstructure of UFG CP Ti [25]. Additionally, it has been proved that for UFG CP Ti the formation of the highly stable oxide layer with higher grain boundary fraction plays an important role in protecting the surface against corrosion [26]. Considering impedance spectrum shown in Fig. 13, it could be revealed that at high frequencies, PEO-coated UFG CP Ti shows a phase angle about $33^{\circ}$ which is closer to $90^{\circ}$ compared with CP Ti and UFG P-Ti and PEO-coated CG CP Ti. Since it has been proved that pure capacitor behavior is plotted as a positive value of $90^{\circ}$, it could be concluded that the coating response is closer to pure capacitive and for the case of PEO-coated UFG CP Ti the corrosion rate is reduced significantly [57].
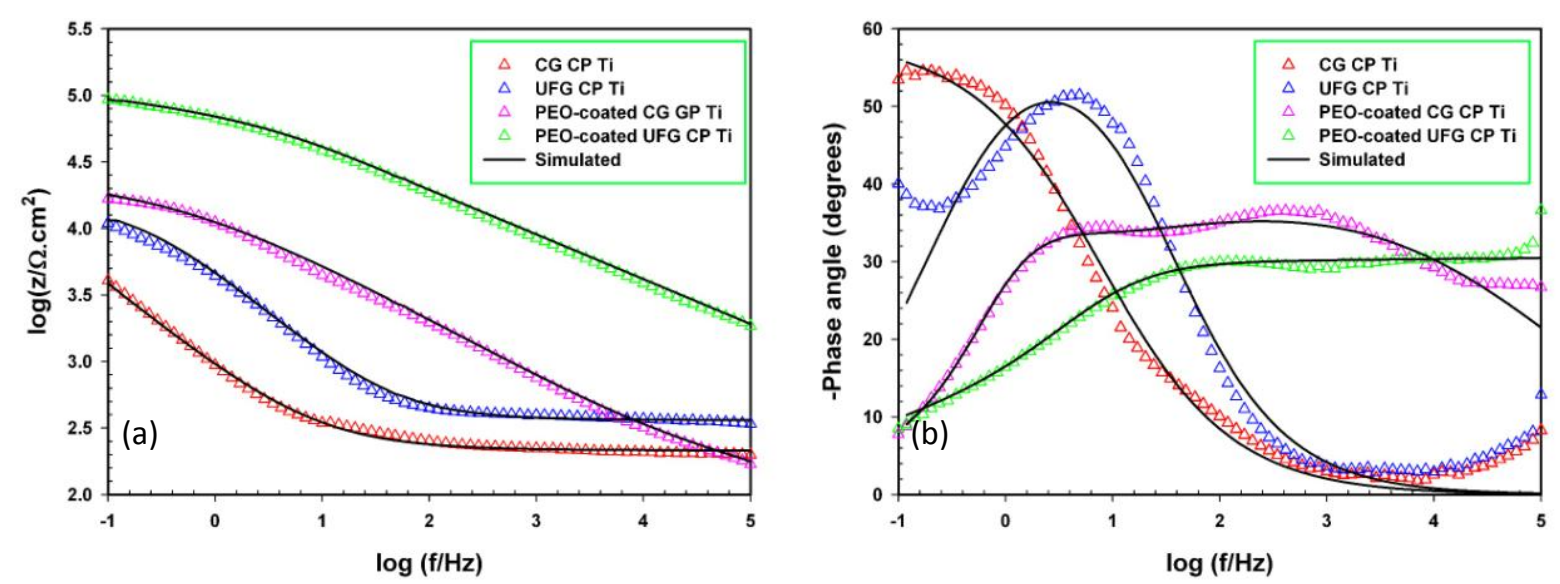

Fig. 13. Bode diagrams resulted from EIS of CG CP Ti, UFG CP Ti, PEO-coated CG CP Ti and PEOcoated UFG CP Ti in Ringer's solution. 


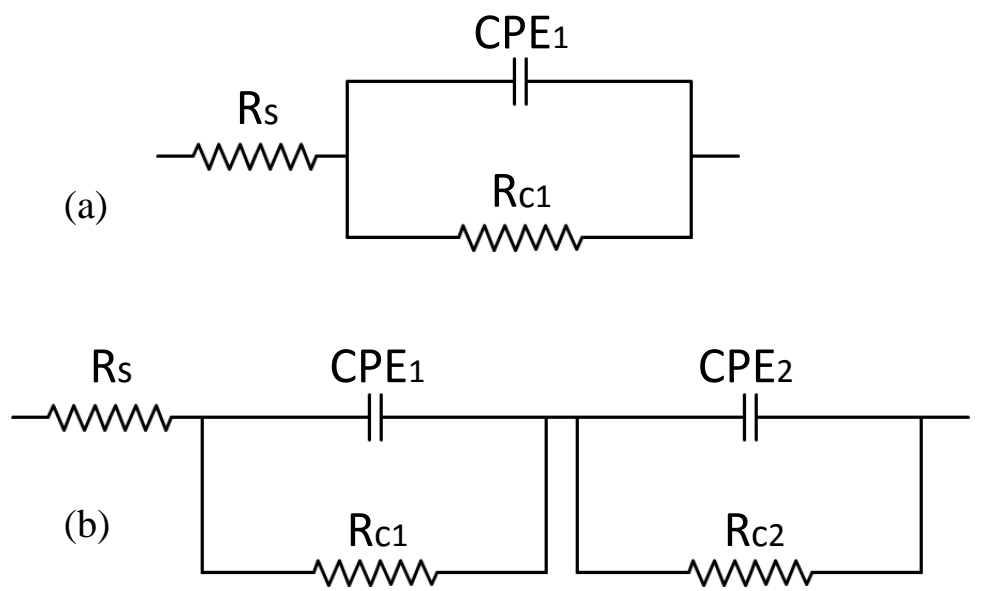

Fig. 14. EEC model for simulating EIS data for (a) CG CP Ti and UFG CP Ti and (b) PEO-coated CG CP Ti and PEO-coated UFG CP Ti.

According to Fig. 14, a more general constant phase element was taken into consideration instead of a capacitive element so as to achieve the best fitting quality by considering the surface inhomogeneity factor. The CPE impedance is defined by the following equation [48]:

$Z_{C P E}=\frac{1}{Q(j \omega)^{n}}$

in which $Q$ is the CPE constant, $j$ is the imaginary unit, $\omega$ is the angular frequency and $n$ takes a value between 0 and 1 . It should be noticed that values 0 and 1 for $n$ determine the CPE to be a pure resistor and a pure capacitor, respectively.

The corresponding circuit parameters resulted from the EIS data are presented in Table 1. It could be revealed from Table 1 that for PEO-coated samples, the resistance $R_{1}$ of the compact inner layer is far higher than the resistance $R_{2}$ of porous outer layer. As a result, it can be concluded that the porous outer layer contribute less to the protection of substrate against corrosion and the resistance of coating depends on the impact inner layer. Furthermore, the corrosion resistance of compact inner layer related to PEOcoated UFG CP Ti is far higher than that of PEO-coated UFG CP Ti which is in consistent with prepared cross-sectional SEM micrographs of samples. 
Table 1 EEC component values calculated by simulating empirical EIS data implementing the EEC depicted in Fig. 14.

\begin{tabular}{ccccccccccc}
\hline Samples & $\begin{array}{c}R_{s} \\
\left(\Omega \cdot \mathrm{cm}^{2}\right.\end{array}$ & $\begin{array}{c}C P E_{d l} \\
\left(\Omega^{-1} \cdot \mathrm{s}^{n} \cdot \mathrm{cm}^{-2}\right)\end{array}$ & $\begin{array}{c}R_{c t} \\
\left(\Omega \cdot \mathrm{cm}^{2}\right)\end{array}$ & $\begin{array}{c}C P E_{1} \\
\left(\Omega^{-1} \cdot \mathrm{s}^{n} \cdot \mathrm{cm}^{-2}\right)\end{array}$ & $\begin{array}{c}R_{c 1} \\
\left(\Omega \cdot \mathrm{cm}^{2}\right)\end{array}$ & $\begin{array}{c}C P E_{2} \\
\left(\Omega^{-1} \cdot \mathrm{s}^{n} \cdot \mathrm{cm}^{-2}\right)\end{array}$ & $\begin{array}{c}R_{c 2} \\
\left(\Omega \cdot \mathrm{cm}^{2}\right)\end{array}$ & $n_{1}$ & $n_{2}$ & $\chi$ \\
\hline CG CP Ti & 215 & $3.6 \times 10^{-5}$ & $6.4 \times 10^{3}$ & - & - & - & - & 0.65 & - & $4.0 \times 10^{-3}$ \\
UFG CP Ti & 271 & $4.6 \times 10^{-5}$ & $1.1 \times 10^{4}$ & - & - & - & - & 0.77 & - & $4.4 \times 10^{-3}$ \\
PEO-coated & 210 & - & - & $2.8 \times 10^{-5}$ & $2.8 \times 10^{4}$ & $5.3 \times 10^{-5}$ & $0.9 \times 10^{2}$ & 0.81 & 0.44 & $1.0 \times 10^{-3}$ \\
CG CP Ti & & - & - & $3.2 \times 10^{-6}$ & $8.2 \times 10^{4}$ & $3.9 \times 10^{-6}$ & $1.0 \times 10^{3}$ & 0.44 & 0.39 & $2.9 \times 10^{-4}$ \\
PEO-coated & 235 & - & - & & & & & \\
UFG CP Ti & & & & & & & & &
\end{tabular}

\section{Conclusions}

UFG CP Ti was prepared by applying four passes of route Bc ECAP on the CP Ti Grade 2. The mechanical properties of CP Ti including hardness, the yield strength, and ultimate tensile strength were enhanced significantly. It was found out that the attained strength of UFG CP Ti is higher than that of Ti64 and the microhardness are almost the same. PEO coating was developed on the CG CP Ti and UFG $\mathrm{CP}$ Ti by applying PEO process at $350 \mathrm{mAcm}^{-2}$ in an electrolyte solution of $0.15 \mathrm{M}$ calcium acetate hydrate and $0.075 \mathrm{M}$ sodium hypophosphite hydrate at a ratio of $1: 1 \mathrm{wt} \%$. It was revealed that the coating had a porous morphology consisting of many micropores and nanopores. The microhardness of PEO-coated CG CP Ti and PEO-coated UFG CP Ti were $3190 \mathrm{MPa}$ and $3275 \mathrm{MPa}$, respectively which were noticeably higher than the microhardness of UFG CP Ti. XRD analysis proved that HA crystallites were formed in the PEO-coating UFG CP Ti, while no peaks related to HA were observed on PEO-coated CG CP Ti. EIS test results indicated that the corrosion resistance of PEO-coated UFG CP Ti was higher than CP Ti, UFG CP Ti, and PEO-coated CG CP Ti. The two primary deficiencies regarding the application of CP Ti in the field of implant industry are solved successfully. Namely, the low mechanical strength is enhanced by implementing ECAP procedure, and the relative low corrosion resistance is increased by applying a coating through PEO process.

\section{Acknowledgements}

This work was financially supported by Iran National Science Foundation (INSF).

\section{References}

[1] D. BomBač, M. Brojan, P. Fajfar, F. Kosel, R. Turk, RMZ-Materials and Geoenvironment 54 (2007) 471-499.

[2] C. Elias, J. Lima, R. Valiev, M. Meyers, Jom 60 (2008) 46-49. 
[3] A. Sidambe, I. Figueroa, H. Hamilton, I. Todd, Journal of Materials Processing Technology 212 (2012) 1591-1597.

[4] P.G. Laing, A.B. Ferguson, E.S. Hodge, Journal of biomedical materials research 1 (1967) 135-149.

[5] S. Steinemann, Evaluation of biomaterials (1980).

[6] S. Steinemann, Titanium--Science and Technology. 2 (1984) 1373-1379.

[7] V. Segal, Materials Science and Engineering: A 271 (1999) 322-333.

[8] V. Segal, Materials Science and Engineering: A 197 (1995) 157-164.

[9] X. Zhao, X. Yang, X. Liu, X. Wang, T.G. Langdon, Materials Science and Engineering: A 527 (2010) 6335-6339.

[10] D. Gunderov, A. Polyakov, I. Semenova, G. Raab, A. Churakova, E. Gimaltdinova, I. Sabirov, J. Segurado, V. Sitdikov, I. Alexandrov, Materials Science and Engineering: A 562 (2013) 128-136.

[11] I. Kim, J. Kim, D.H. Shin, K.-T. Park, Metallurgical and Materials Transactions A 34 (2003) 1555-1558.

[12] R.Y. Lapovok, Journal of Materials Science 40 (2005) 341-346.

[13] G. Raab, E. Soshnikova, R. Valiev, Materials Science and Engineering: A 387 (2004) 674-677.

[14] R.Z. Valiev, T.G. Langdon, Progress in Materials Science 51 (2006) 881-981.

[15] R. Bhola, S.M. Bhola, B. Mishra, D.L. Olson, Trends in Biomaterials and Artificial Organs 25 (2011) 34-46.

[16] M. Nie, C.T. Wang, M. Qu, N. Gao, J.A. Wharton, T.G. Langdon, Journal of Materials Science 49 (2014) 2824-2831.

[17] M. Hoseini, A. Shahryari, S. Omanovic, J.A. Szpunar, Corrosion science 51 (2009) 3064-3067.

[18] L. Le Guéhennec, A. Soueidan, P. Layrolle, Y. Amouriq, Dental materials 23 (2007) 844-854.

[19] A. Yerokhin, A. Leyland, A. Matthews, Applied Surface Science 200 (2002) 172-184.

[20] Y. Wang, T. Lei, B. Jiang, L. Guo, Applied surface science 233 (2004) 258-267.

[21] W. Simka, A. Sadkowski, M. Warczak, A. Iwaniak, G. Dercz, J. Michalska, A. Maciej, Electrochimica Acta 56 (2011) 8962-8968.

[22] M. Shokouhfar, C. Dehghanian, M. Montazeri, A. Baradaran, Applied Surface Science 258 (2012) 2416-2423.

[23] S. Aliasghari, A. Němcová, P. Skeldon, G. Thompson, Surface and Coatings Technology 289 (2016) 101-109.

[24] E. Matykina, R. Arrabal, B. Mingo, M. Mohedano, A. Pardo, M. Merino, Surface and Coatings Technology 307 (2016) 1255-1264.

[25] E.M. Campos, A. Santos-Coquillat, B. Mingo, R. Arrabal, M. Mohedano, A. Pardo, V. Ramos, J.-L.L. Lacomba, E. Matykina, Surface and Coatings Technology 283 (2015) 44-51.

[26] X. Lu, M. Mohedano, C. Blawert, E. Matykina, R. Arrabal, K.U. Kainer, M.L. Zheludkevich, Surface and Coatings Technology 307 (2016) 1165-1182.

[27] N. Somsanith, T.S. Narayanan, Y.-K. Kim, I.-S. Park, T.-S. Bae, M.-H. Lee, Applied Surface Science 356 (2015) 1117-1126.

[28] M.R. Shankar, B.C. Rao, S. Lee, S. Chandrasekar, A.H. King, W.D. Compton, Acta Materialia 54 (2006) 3691-3700.

[29] V. Chuvil'deev, V. Kopylov, A. Bakhmet'ev, N. Sandler, A. Nokhrin, P. Tryaev, Y.G. Lopatin, N. Kozlova, A. Piskunov, N. Melekhin, Effect of the simultaneous enhancement in strength and corrosion resistance of microcrystalline titanium alloys, in: Doklady Physics, vol 57, Springer, 2012, pp. 10-13.

[30] B. Mingler, V. Stolyarov, M.J. Zehetbauer, W. Lacom, H.P. Karnthaler, TEM investigations of Titanium processed by ECAP followed by cold rolling, in: Materials Science Forum, vol 503, Trans Tech Publ, 2006, pp. 805-810.

[31] K. Hajizadeh, S.G. Alamdari, B. Eghbali, Physica B: Condensed Matter 417 (2013) 33-38.

[32] S. Suwas, B. Beausir, L. Tóth, J.-J. Fundenberger, G. Gottstein, Acta Materialia 59 (2011) 1121-1133. 
[33] Y. Chen, Y. Li, J. Walmsley, S. Dumoulin, S. Gireesh, S. Armada, P. Skaret, H. Roven, Scripta Materialia 64 (2011) 904-907.

[34] P. Scherrer, Bestimmung der inneren Struktur und der Größe von Kolloidteilchen mittels Röntgenstrahlen, in: Kolloidchemie Ein Lehrbuch, Springer, 1912, pp. 387-409.

[35] B.R. Rehani, P. Joshi, K.N. Lad, A. Pratap, (2006).

[36] G. Faraji, H. Kim, Materials Science and Technology (2016) 1-19.

[37] M. Niinomi, Materials Science and Engineering: A 243 (1998) 231-236.

[38] S. Stojadinović, R. Vasilić, M. Petković, L. Zeković, Surface and Coatings Technology 206 (2011) 575581.

[39] D. Veys-Renaux, Z.A. El Haj, E. Rocca, Surface and Coatings Technology 285 (2016) 214-219.

[40] T. Hryniewicz, K. Rokosz, R. Rokicki, Magnetoelectropolished titanium biomaterial, INTECH Open Access Publisher, 2011.

[41] D. Quintero, O. Galvis, J. Calderón, J. Castaño, F. Echeverría, Surface and Coatings Technology 258 (2014) 1223-1231.

[42] S. Moon, Y. Jeong, Corrosion Science 51 (2009) 1506-1512.

[43] L. Wang, L. Chen, Z. Yan, W. Fu, Surface and Coatings Technology 205 (2010) 1651-1658.

[44] Z. Wang, N. Tao, W. Tong, J. Lu, K. Lu, Acta Materialia 51 (2003) 4319-4329.

[45] W. Tong, N. Tao, Z. Wang, H. Zhang, J. Lu, K. Lu, Scripta Materialia 50 (2004) 647-650.

[46] R.A. Surmenev, M.A. Surmeneva, A.A. Ivanova, Acta biomaterialia 10 (2014) 557-579.

[47] S. Bagherifard, R. Ghelichi, A. Khademhosseini, M. Guagliano, ACS applied materials \& interfaces 6 (2014) 7963-7985.

[48] M. Montazeri, C. Dehghanian, M. Shokouhfar, A. Baradaran, Applied Surface Science 257 (2011) 7268-7275.

[49] K.R. Shin, Y.S. Kim, G.W. Kim, Y.G. Ko, D.H. Shin, Colloids and Surfaces B: Biointerfaces 131 (2015) 47-53.

[50] M. Bramowicz, L. Braic, F.A. Azem, S. Kulesza, I. Birlik, A. Vladescu, Applied Surface Science 379 (2016) 338-346.

[51] H. Zhang, L. Wang, Z. Hei, G. Liu, J. Lu, K. Lu, Zeitschrift für Metallkunde 94 (2003) 1143-1147.

[52] Z. Wang, J. Lu, K. Lu, Acta Materialia 53 (2005) 2081-2089.

[53] W. Tong, N. Tao, Z. Wang, J. Lu, K. Lu, Science 299 (2003) 686-688.

[54] C. Fei, Z. Hai, C. Chen, X. Yangjian, Progress in Organic Coatings 64 (2009) 264-267.

[55] A. Ghasemi, V. Raja, C. Blawert, W. Dietzel, K. Kainer, Surface and Coatings Technology 202 (2008) 3513-3518.

[56] J.I. Langford, A. Wilson, Journal of Applied Crystallography 11 (1978) 102-113.

[57] D. Qiu, L. Yang, Y. Yin, A. Wang, Surface and Coatings Technology 205 (2011) 3280-3284. 


\section{Figure captions}

Fig. 1. Schematic illustration of ECAP and plasma electrolytic oxidation processes.

Fig. 2. ECAP die half and Ti sample during processing.

Fig. 3. SEM microstructures of (a) CG CP Ti and (b) UFG CP Ti processed by four passes ECAP.

Fig. 4. XRD patterns of CG CP Ti and UFG CP Ti.

Fig. 5. Strength and ductility of CG CP Ti, UFG CP Ti, and Ti64 samples.

Fig. 6. Microhardness of CG CP Ti, UFG CP Ti, PEO-coated CG CP Ti, PEO-coated UFG CP Ti and Ti64 samples.

Fig. 7. Cell voltage during PEO process for of (a) CG CP Ti and (b) UFG CP Ti during 480 seconds.

Fig. 8. SEM views of PEO-coated of (a), (b) CG CP Ti surface and (c), (d) UFG CP Ti surface.

Fig. 9. SEM views showing cross sections of PEO coating formed on (a) CG CP Ti and (b) UFG CP Ti substrates.

Fig. 10. The distribution of pores size in the coating for PEO-coated CG CP Ti and PEO-coated UFG CP Ti.

Fig. 11. EDS spectra of PEO-coated CG CP Ti and UFG CP Ti surfaces.

Fig. 12. XRD patterns of (a) PEO-coated CG CP Ti and (b) PEO-coated UFG CP Ti.

Fig. 13. Bode diagrams resulted from EIS of CG CP Ti, UFG CP Ti, PEO-coated CG CP Ti and PEOcoated UFG CP Ti in Ringer's solution.

Fig. 14. EEC model for simulating EIS data for (a) CG CP Ti and UFG CP Ti and (b) PEO-coated CG CP Ti and PEO-coated UFG CP Ti. 


\section{Table captions}

Table 1. EEC component values calculated by simulating empirical EIS data implementing the EEC depicted in Fig. 14. 


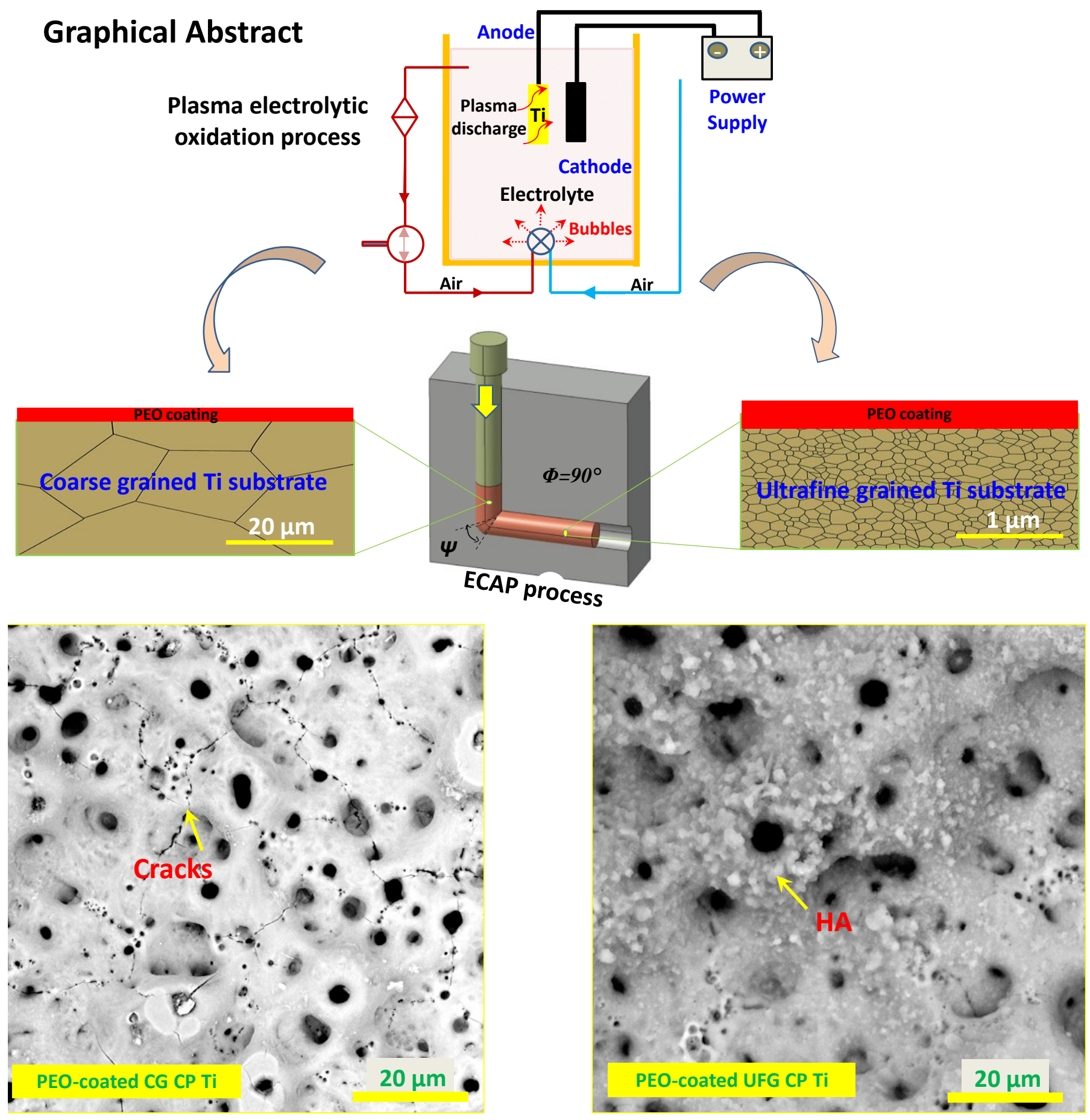

